\title{
CONSIDERACIONES ESTRUCTURALES SOBRE LA ODA
}

\author{
María Victoria Utrera Torremocha
}

\begin{abstract}
This study will consider the genre of the ode in its various textual forms, from the classical period until the twentieth century. Taking as its starting point the relationship between the ode and other related forms, the basic features of the ode are established.Its interrelationships with, and influences on, other generic types lend it an essentially historical quality, making it a dynamic genre which -whilst following a basic line-is transformed according to the cultural and artistic demands of each given historical period. This is the case during the Romantic period, in which classical precepts give way to new approaches to literary forms. This shift allows the ode to absorb the influence of other genres such as the meditative poem, and gives it validity within the new spiritual framework. This new form of ode will, with certains variations, continue and develop historically throughout the twentieth century.
\end{abstract}

El estudio de los géneros literarios suele estar basado en los rasgos estructurales de los mismos, aunque es evidente que ninguna modalidad genérica permanece inmutable en el tiempo y que tampoco se presenta en cada caso particular como igual y exacta a un posible modelo. Las variaciones históricas, con peculiaridades específicas en las distintas literaturas, pueden explicar la revolución literaria desde un punto de vista interno ${ }^{1}$ y son esenciales en la aparición de nuevas estructuras. Sin perder de vista este planteamiento de carácter histórico, podría decirse, no obstante, que las diversas manifestaciones son susceptibles de ser agrupadas de acuerdo con los rasgos formales y estructurales específicos que afectan, o pueden afectar según los casos, a lo que Wellek y Warren llaman forma exterior e interior. ${ }^{2}$ Los rasgos fundamentales están integrados, Así, en el propio sistema literario, del que el autor no siempre puede desprenderse. Los géneros, entendidos como instituciones que responden a un conjunto de reglas y a un tipo previo de discurso, determinan, en cierta medida, la literariedad de los textos, al menos en lo que concierne a su producción y a su recepción. ${ }^{3}$ En algunas ocasiones,

\footnotetext{
${ }^{1}$ Cfr. M.A. Garrido Gallardo, "Los géneros literarios", en Estudios de semiótica literaria (Madrid, CSIC, 1982), pp. 94-95; T. Todorov, "Genres littéraires", en O. Ducrot y T. Todorov, Dictionnaire encyclopédique des sciences du language (París, Seuil, 1972), pp. 193 y ss.; A. García Berrio y M.T. Hernández Fernández, La Poética: tradición y modernidad (Madrid, Síntesis, 1988), p. 121

${ }^{2}$ R. Wellek y A. Warren, Teoría literaria (Madrid, Gredos, 1974), p. 278.

3 Vide M.A. Garrido Gallardo, art. cit., pp. 93-94; H. Levin, "Literature as an Institution", Accent, VI (1946), pp. 15968; R. Wellek y A. Warren, op. cit., pp. 271 y ss.; F. Abad, Los géneros literarios y otros estudios de filología (Madrid, UNED, 1982), pp. 93-94; C. di Girolamo, Teoría crítica de la literatura (Barcelona, Crítica, 1982), p. 98; J. Culler, La poética estructuralista (Barcelona, Anagrama, 1978), pp. 47-54.
} 
el convencional prestigio literario de un tipo genérico tradicional puede ser el motivo de que algún escritor lo recupere como modo de afirmación literaria personal.

La oda y el himno son tipos genéricos tradicionalmente incluidos en la lírica. Ésta ha sido caracterizada de diversas maneras a lo largo de la historia de la teoría de los géneros literarios; pero no siempre se le ha prestado la atención que actualmente se le otorga, como sucedía ya en la Poética de Aristóteles, que marcó la pauta en la carencia de una tradición seria en la tipología y caracterización de la poesía lírica. Hasta Hegel, el ideal de la lírica era el de la multiplicidad de materias. ${ }^{4}$ Con él la lírica queda sistematizada y delimitada, mediante el rasgo básico común del subjetivismo, junto con los otros dos géneros, épico y dramático, dentro de la ya clásica división tripartita. El planteamiento reciente de que la lírica se fundamenta en la expresión del sentir vital y anímico de sus autores es, pues, reciente. No cabe duda de que se sigue un camino abierto por los pre-románticos. Ya Goethe entendía la lírica como una exaltación emocional, rasgo que se ha elevado a categoría fundamental de lo lírico. Asimismo, y más recientemente, Staiger entiende lo lírico como la interiorización de lo objetivo, al igual que Kayser, quien, siguiendo también a Goethe, caracteriza la lírica como excitación personal entusiasmada. La actitud lírica básica sería, por tanto, hacer subjetivo lo objetivo, aspecto que se mantiene como fundamento de los géneros líricos en la mayoría de los estudios al respecto del siglo XX. ${ }^{5}$

El himno y la oda nacen en la cultura griega, ligados a la danza y a la música, al deseo de alabanza de los dioses y a la celebración de eventos diversos. El canto podía ser ejecutado por un coro, como atestigua, por ejemplo, Homero. Así es como surge la poesía coral. Como muestra de una civilización y sus valores -ya que son cantos de alabanza- el canto podría tener alguna escena narrativa, centrada a veces en un mito, y también algún tipo de contenido que escondiese un comportamiento moral. Lógicamente el lenguaje está lleno de solemnidad y nobleza, como corresponde al tema tratado, sobre todo en lo que respecta a los cantos dedicados a dioses y héroes. En Esparta, en el siglo VII a. C., comienza una corriente literaria con estas características con Terpandro y, poco después, con Alcmán, único poeta coral de su siglo de quien tenemos versos, donde ya se aprecian las características típicas de la oda, con la presencia de las máximas morales, alusiones personales y mitos. Posteriormente es cuando nace, hacia el 600 a. C., la poesía hímnica y ódica que tendrá gran influencia en toda la literatura posterior, con los poetas de Lesbos. La poesía lírica o mélica -del griego melos, que significa 'canto'-, compuesta entre los siglos VII y V a. C., estaba acompañada de la lira o algún instrumento de viento, o ambos, y podía ser coral, en la línea de los autores de la escuela de Esparta, o monódica, en la que, como su nombre indica, no intervenía el coro, y cuyos principales representantes son Safo y Alceo, junto con Anacreonte. Los cantos eran interpretados por una sola voz, que cantaba pequeñas estrofas, luego conocidas con nombres

\footnotetext{
${ }^{4}$ Vide A. García Berrio, Formación de la teoría literaria moderna. La tópica horaciana en Europa (Madrid, Cupsa, 1977), pp. 95-96.

5 Cfr. F. Lázaro Carreter, "Sobre el género literario", en Estudios de Poética (la obra en sí) (Madrid, Taurus, 1986), pp. 113-120; P. Hernadi, Teoría de los géneros literarios (Barcelona, Bosch, 1978), 12-13; W. Kayser, Interpretación y análisis de la obra literaria (Madrid, Gredos, 1958), pp. 439-443; F. Abad, op. cit., pp. 91-92; M.A. Garrido

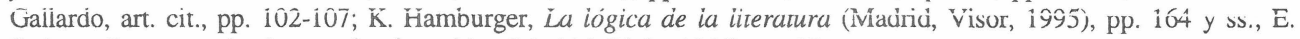
Staiger, Conceptos fundamentales de poética (Madrid, Rialp, 1966), pp. 27 y ss.
} 
específicos: la estrofa sáfica, la alcaica o la anacreóntica. Se trata de una poesía más cercana a la individualidad, más conversacional y personal, con un tono, por tanto, menos solemne y magnífico que la poesía de tipo coral. Esta última, con representantes como Alcmán, Simónides, Píndaro y Baquílides, era cantada y bailada por un coro y su estructura difiere de la monódica especialmente en la métrica, al estar dividida frecuentemente en tres partes que se correspondían con las llamadas estrofa, antistrofa y epodo. Tiene un carácter más público y altamente artificial, con un lenguaje más elaborado y diferentes variantes, de acuerdo con el tema principal tratado: himnos, peanes, ditirambos, epinicios, etc. ${ }^{6}$

En general, en la poesía mélica, aparte de las formas métricas específicas, la estructura de los poemas está bastante definida. Son poemas habitualmente ternarios, con proemios típicos que pueden variar según el subgénero, como el de la invocación al dios, por ejemplo, de algunos himnos, aunque ésta también puede aparecer en las odas. En la parte central la narración o reflexión va acompañada de alusiones al poeta o suele centrarse en el mito, caso, por ejemplo, de Alceo, aunque ya en éste y otros autores existen centros más innovadores, con relatos diversos. Al final, suele haber alguna nueva referencia al mito o se formula el saludo final al dios, o se repite la invocación o la fórmula inicial, con estructura circular, o bien se ofrece la conclusión. La decisión, de carácter conclusivo o resolutivo, es, para Kayser, una "forma interiormente ligada a la actitud ódica" (KAYSER 1958:453). Pero ese final de decisión, posible igualmente en el himno, puede presentarse de otras maneras y concretarse finalmente en admonición, en deseo, etc. La estructura circular se cumple en la práctica totalidad de todos los himnos y odas desde el principio, caso de la "Oda a Afrodita" de Safo, aunque hay variaciones, como ocurre en Horacio, cuyos tipos ódicos estructurales más frecuentes son, además del circular, la composición lineal, con gradación ascendente o descendente, y la bimembre, entre otros. ${ }^{7}$

Aunque se supone que, como género serio, la oda ha de tener una extensión más bien larga, esto no siempre se ha cumplido. Las odas varían mucho entre sí, sobre todo con respecto a la métrica y a la propia estructura. La variedad de la oda puede verse ya desde sus cultivadores clásicos, como Safo, Píndaro y, sobre todo, Horacio, que fueron los principales que les confirieron los rasgos típicos. Henri Morier, en su Dictionnaire de Poétique et de Rhétorique, distingue varios tipos de odas: la pindárica, cultivada después por Ronsard, la oda estrófica, la clásica, con casos como Fray Luis, Medrano o Herrera, las Odas de P. Malherbe, junto a las de Victor Hugo, y la oda simbolista, que tiene su máximo ejemplo en Paul Verlaine. La versificación es, pues, bastante variada. En cualquier caso, las odas clásicas griegas son la

${ }^{6}$ Vide C.M. Bowra, La literatura griega (México, FCE, 1971), pp. 42-45.

${ }^{7}$ Cfr. F. Rodríguez Adrados, Orígenes de la lírica griega (Madrid, Revista de Occidente, 1976), pp. 219-20; C.M. Bowra, Greek Lyric Poetry. From Alcman to Simonides (Oxford, Oxford University Press, 1967), p. 200; H.L. Tracy, "Thought-Sequence in the Ode", Phoenix, 5 (1955), pp. 108-18; G. Willians, The Third Book of Horace's Odes (Oxford, 1969); G. Hinojo Andrés, "La poesía lírica latina", en C. Codoñer (ed.): Géneros literarios latinos (Salamanca, Universidad, 1987), pp. 184-87. 
pindárica, la sáfica, la alcaica, la anacreóntica y la asclepiada, cada una con un tipo de métrica diferente. $^{8}$

Tanto la oda como el himno poseen lo que Kayser ha llamado la "vivencia de una tensión", (KAYSER 1958: 491) hecho que les confiere cierto dramatismo concretado en la apelación. El apóstrofe constituye una de las actitudes básicas de lo lírico, y está siempre presente tanto en el himno como en la oda. Mientras que el himno canta un poder superior, concretado generalmente en un dios, en la oda el "tú" está más cerca del poeta, por lo que el estilo solemne y exaltado del himno da paso a la serenidad de la contemplación y del encuentro y a un lenguaje que, sin perder su nobleza, es reflexivo y pausado. El yo tiene bastante peso en la oda, pues no se diluye en la exaltación exacerbada del himno y, por lo tanto, se hace más humano y también más asequible al lector, "más tangible" y familiar, acorde con el tema de la oda, que suele ser igualmente más real y cercano. Pero en la oda pueden aparecer también, como en el himno, poderes superiores. En ambos casos, la figura de la interpelación, muy presente, por otro lado, en buena parte de las manifestaciones de la lírica, como señala Paul de Man, es la básica, "hasta el extremo de constituir la definición genérica de, como mínimo, la oda (que, a su vez, se puede considerar paradigmática de la poesía en general)." $"$

Los temas que la oda trata son bastante variados, hasta el punto de que no se puede decir que el tema defina la oda. A menudo está dedicado a personas elevadas, o a ciudades y paisajes, todo ello acompañado de una reflexión contemplativa en la que se menciona la existencia personal y colectiva, con temas como el carpe diem y el beatus ille, provenientes de Horacio. Como resulta que la oda es algo sentenciosa, en algunos casos y, según el tema tratado, puede derivar hacia la sátira, dando lugar a las odas satíricas, que se alejan de la oda clásica. Además podemos encontrar que las referencias personales del poeta pueden tomar cuerpo en toda la oda. Así, un tipo de oda es la que trata el proceso creador o el quehacer artístico del poeta, caso también clásico, como se aprecia en Horacio -"Pindarum quisquis studet aemulari"-, en Fray Luis de León -"Oda a Salinas"- y, mucho más tarde, en Federico García Lorca -"Oda a Salvador Dalí".

El himno tiene originalmente un carácter religioso, ya que está dirigido en muchísimas ocasiones a divinidades, a veces también a héroes y abstracciones superiores. Los fragmentos de Simónides, Baquílides o Píndaro, por ejemplo, fueron probablemente cantados como poemas religiosos. Como una forma interior característica de los himnos, se encuentra "la alabanza de lo divino, de lo numioso", ${ }^{10}$ por lo que suelen implicar un diálogo relativo entre dioses y hombres.

\footnotetext{
${ }^{8}$ Vide H. Morier, Dictionnaire de Poétique et de Rhétorique (París, PUF, 1975).; A. García Berrio y J. Huerta Calvo, Los géneros literarios: sistema e historia (Madrid, Cátedra, 1992), p. 153; W. Kayser, op. cit., pp. 115-7; D. Page, Sappho and Alcaeus. An Introduction to the Study of Ancient Lesbian Poetry (Oxford, Clarendon Press-Oxford University Press, 1975), pp. 323-326.

${ }^{9}$ P. de Man, La resistencia a la teoría (Madrid, Visor, 1990), p. 77

${ }^{10}$ Kayser, op. cit., p. 453. A veces el himno en su faceta enunciativa se puede convertir en proclamación, dadas las afinidades estilísticas entre himno y proclamación. Vide M.A. Garrido Gallardo, "Géneros literarios", en D. Villanueva (coord.), Curso de teoría de la literatura (Madrid, Taurus, 1994), pp. 181-182. Algunos incluyen dentro de
} 
Dentro de los tipos hímnicos, cabe destacar el lírico, en su origen de carácter míticoreligioso, y el litúrgico. El primero surge en Grecia con Calímaco y Píndaro, con escaso cultivo en Roma a excepción del Carmen Saeculare de Horacio, modelo para los tiempos posteriores, y que otros califican como una oda. El segundo nace con el cristianismo y se desarrolla en la Edad Media, manteniéndose actualmente con algunas variaciones. Se trata de un canto de alabanza a Dios, a la Virgen o los santos. Procede de San Ambrosio y de la posterior práctica monacal del Officium horarum y ha ido modernizándose y emancipándose. El himno surge del ámbito religioso para pasar después a extender sus temas hacia lo heroico, los ideales, los soberanos, lugares, países o fenómenos destacados. Ejemplos de estos últimos son el "Himno a la luna" de Jovellanos, el "Himno al sol" de Espronceda y más recientemente el Cántico de Jorge Guillén, en el que se exaltan la alegría de vivir y la perfección del mundo."

Píndaro ha sido la fuente fundamental de toda la poesía hímnica europea posterior, junto con la fuente bíblica de los salmos. En los poemas de Píndaro la exaltación de los dioses se hace a través de la exaltación de sus poderes, su principal atributo. Como después en la obra de Hölderlin, el mundo literario de Píndaro está lleno de dioses y hombres en continua comunicación mágica y presenta a los héroes como una clase intermedia entre ellos. Otra fuente importante para los himnos actuales, así como para las odas, es el himno de Calímaco, derivado de los himnos homéricos, más narrativos, con una estructura similar a la tripartita, que será repetida después en composiciones como la "Ode to Psyche", de Keats, entre otras. ${ }^{12}$

El himno, por tanto, reúne intenciones litúrgicas y literarias. En su evolución, asimila varias tradiciones, como la oriental de la literatura hebrea, que tanto peso tendría después en los himnos cristianos, sobre todo a través de las traducciones de la Biblia, la Vulgata y también en los escritos griegos y latinos de los Padres de la Iglesia, tradición que llega hasta el siglo veinte. Cuando los setenta traductores tuvieron que traducir el Antiguo Testamento usaron los términos himnos y salmos, así como oda y plegaria, entre otros. Muchos salmos bíblicos se identificaron como himnos. La atribución a los salmos de los nombres de la oda y del himno hace ver las similitudes entre ambos conceptos. Incluso en algunos pasajes del Nuevo Testamento los tres términos, salmo, oda, e himno, se mencionan como equivalentes. ${ }^{13}$ En sus Confesiones, San Agustín señala la introducción de himnos y salmos cantados en Milán por Ambrosio. El himno, por su carácter ancestral, sí es nombrado, aunque no estudiado detenidamente, en las Etymologiae de San Isidoro de Sevilla, quien se refiere a él por el deseo de sobreponer la literatura bíblica a la clásica, haciendo ver que aparece en la Biblia en los

la literatura hímnica al ditirambo y a los himnos fálicos, ambos como partes de los rituales dionisíacos. Otra variedad hímnica sería el peán, el epinicio, el himeneo y la canción erótica. Cfr. F. Rodríguez Adrados, Fiesta, tragedia, comedia. Sobre los orígenes griegos del teatro (Barcelona, Planeta, 1972), pp. 21 y ss., y Orígenes de la lírica griega, pp. 75-92.

11 Vide K. Spang, Géneros literarios (Madrid, Síntesis, 1993), pp. 85-86.

${ }^{12}$ Cfr. C.M. Bowra, Pindar (Oxford, Oxford University Press, 1971), pp. 44 y ss.; K. Spang, op. cit., p. 448.

${ }^{13}$ En la literatura oriental, hebreos y hetitas el himno o salmo es fundamental, en forma de elogio o súplica al dios. En general se consideran como monodia, pero hay indicios de que en Mesopotamia, Jerusalén y Egipto se cantaban con la intervención de un coro y como un tipo de lírica dialógica. Vide F. Rodríguez Adrados, Orígenes de la lírica griega, pp. 195-96. 
himnos de David, de modo que identifica los salmos de David como modalidad hímnica y especifica que deben orar a Dios y ser cantados, aunque en otro lugar indica que Hilary de Poitiers compuso himnos de celebración dedicados a santos y mártires (De ecclestiacis officiis).$^{14}$

No es fácil determinar los límites entre el himno y la oda. Los términos oda e himno se intercambian en ocasiones como términos sinónimos. La "Oda a la Alegría" de Schiller, usada en el movimiento final de la novena sinfonía de Beethoven, es calificada generalmente como himno. La confusión afecta también a la obra de otros autores, como ocurre, por ejemplo, con Píndaro y Hölderlin.

La citada confusión se debe, sin duda, a las similitudes estructurales entre ambos géneros. El himno comparte la estructura ternaria de la oda. A veces el tono personal invade el centro. Como apunta F. Rodríguez Adrados, con tanta variedad hímnica, formas mixtas de enunciación, himnos derivados, apóstrofe no sólo al dios, sino a seres divinizados o abstractos, personalización excesiva del poeta y otro tipo de desviaciones, la "forma hímnica puede convertirse en una especie de marco", ${ }^{15}$ de manera que quizás lo único que quedaría como rasgo característico que lo aleja de la oda sería el tono exaltado.

En la historia de la oda y del himno han existido contaminaciones mutuas, de ahí que no siempre se entiendan de igual manera cada uno de los términos, ni se puedan ofrecer límites precisos y absolutos. Es, sobre todo, con la aparición pujante de la lírica a partir de los siglos XIV y XV cuando algunos teóricos comienzan a preocuparse por los géneros líricos. Así, entre otros, el italiano Giovan Giorgio Trissino afirma en 1529 que "cuando el poeta habla siempre en su persona y no introduce otras personas que hablen" encontramos "las Elegías, las Odas, las Canciones", etc., caracterización global de la lírica como género ligado a la primera persona, en la que se menciona ya un género tan clásico como la oda. Minturno se refiere también al epigrama y al himno, incorporando la lírica al cuadro genérico. (GARCÍA BERRIO-HUERTA CALVO 1992: 114; GARCÍA BERRIO-HERNÁNDEZ FERNÁNDEZ 1988: 23-24) El Pinciano es buen ejemplo de la confusión con respecto a la lírica. En su Philosophía Antigua Poética señala que "dithirámbica, zarabanda y lírica todo es una misma cosa", ${ }^{16}$ y atribuye a la lírica rasgos como la exhortación y la alabanza, entre otros, elementos que, desde luego, se pueden aplicar tanto al himno como a la oda, por lo que estos géneros

\footnotetext{
14 Respecto a otros géneros, habla de poemas heroicos, elegíacos y bucólicos, de acuerdo con una clasificación temática. También nombra, junto con el himno, el epitalamio, el treno, el epitafio, el epigrama, el épodo y la fábula como géneros de la Antigüedad. Vide A. García Berrio y J. Huerta Calvo, op. cit., pp. 106-7.

15 De hecho, la "Oda a Afrodita" de Safo (fragmento 1) es una repetición de este esquema. Cfr. F. Rodríguez Adrados, Orígenes de la lírica griega, pp. 220-234. Para K. Spang el himno es quizá una forma lírica más exaltada y solemne, cuyo sujeto suele ser la primera persona del plural que apostrofa a un tú. No son propias del himno las descripciones, aunque sí existen, como en la oda, el dinamismo versátil, apóstrofes, digresiones y la autopresentación del poeta, junto a sus circunstancias personales. Cfr. K. Spang, op. cit., pp. 85-86; R. Lapesa, Introducción a los estudios literarios (Madrid, Cátedra, 1971), p. 141; A. García Berrio y J. Huerta Calvo, op. cit., p. 153.

${ }^{16}$ A. López Pinciano, Philosophía Antigua Poética (ed. Alfredo Carballo Picazo, Madrid, CSIC, Instituto "Miguel de Cervantes", 1953), vol. III, p. 93. Vide S. Shepard, El Pinciano y las teorías literarias del Siglo de Oro (segunda edición aumentada, Madrid, Gredos, 1970), p.129.
} 
serían considerados implícitamente líricos por Pinciano. De hecho, ofrece un ejemplo muy significativo de lo que considera poeta lírico, citando a Petrarca y su himno "Vergine bella che di sol vestita", junto con otro atribuido a Aristóteles, un elogio de Hermia, la ateniense. Tomás Correa, por su parte, habla de la lírica como canto a los dioses y a otros:"...lyricis versibus cani solere Deorum laudes, et eorum..."17 El Brocense ve en el himno el género dedicado a dioses y a héroes: "Hymni, et laudes Deorum, et Heroum in hoc genere scripti sunt. Victores in olympiis et caeteris ludis hoc carmine celebrantur", ${ }^{18} \mathrm{y}$, en sus comentarios a Garcilaso (1570), menciona la oda horaciana, incluyendo en sus notas algunas traducciones de Horacio hechas por Fray Luis de León, también, como Garcilaso, en liras. Herrera en las Anotaciones a Garcilaso (1580), sin embargo, y quizás por antipatía al Brocense, no emplea en ningún momento la denominación de "Ode ad Florem Gnidi", sino que se refiere a ella siempre como Canción V, en la estela de la canción petrarquista. Evidentemente, como se aprecia en sus comentarios, conocía muy bien la tradición de la oda horaciana y explica el término oda de acuerdo con su sentido etimológico. Sin embargo, no quiso hacer distinciones entre la oda horaciana y la canzone italiana. ${ }^{19}$

Será mucho más tarde, en 1674, cuando se defina y caracterice la oda de manera más concreta y específica a partir de sus peculiaridades estilísticas. Así, Boileau en L'Art poétique se refiere al ímpetu, el esplendor, la energía y la vehemencia del estilo de la oda, que va acompañado de un bello desorden y que, sin duda, es el resultado de una inteligente y cuidadosa vigilancia poética: "Son style impétueux souvent marche au hasard, / chez elle un beau désordre est un effet de l'art." ${ }^{20}$ La relación de la oda con el mundo celeste y glorioso y la comparación que se hace entre la oda y la abeja implica su condición divina y misteriosa, que hace envidiable su estilo fogoso al mismo Apolo. No ha de olvidarse, en este sentido, la frecuente comparación entre poesía y miel, como entre poeta y abeja, en la obra de Píndaro. En la caracterización de Boileau se pueden observar claros ecos del concepto de lo sublime vehemencia, ímpetu, intensidad, etc.- ${ }^{21}$ que Longino desarrolla en el tratado que N. Boileau tradujo, con Despréaux, también en 1674. La relación entre sublimidad y oda permitiría, por tanto, situar este género en un nivel importante dentro del cuadro genérico, aunque nunca a la misma altura de los grandes géneros, la epopeya, la tragedia y la comedia.

17 Tomás Correa, In Librum de Arte Poetica Q. Horatii Flacci Explanationes (Venecia, ap. F. de Franciscis, MDLXXXVII, ed. facsimilar, Munich, W. Fink, 1969), p. 38; en A. García Berrio, Formación de la teoría literaria moderna, p. 96.

18 F. Sánchez de las Brozas, In Artem Poeticam Horatii Annotationes (Salamanca, 1591), en Opera Omnia (ed. de Gregorio Mayans, Ginebra, MDCCLXVI), vol II, p. 119; en A. García Berrio, Formación de la teoría literaria moderna, p. 95.

${ }^{19}$ Vide F. de Herrera, Obras de Garcilaso de la Vega con Anotaciones de F. de Herrera (ed. facsimilar, prólogo de A. Gallego Morell, Madrid, CSIC, 1973), p. 220; E.L. Rivers, Muses and Masks: Some Classical Genres of Spanish Poetry (Newark (Delaware), Juan de la Cuesta, 1992), pp. 25-26.

${ }^{20}$ N. Boileau, L'Art poétique (París, Bordas, 1972), canto II, vv. 58-81, pp. 58-60. La relación del poeta con los dioses aparece también en el Ión de Platón y en la Epístola a los Pisones (vv. 83-85) de Horacio.

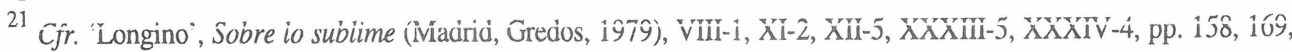
171,200 y 202 , respectivamente. 
En efecto, como señala M.H. Abrams, en El espejo y la lámpara, las poesías líricas se tuvieron por cosa poco provechosa, como si fueran de un rango inferior frente a otras modalidades literarias, planteamiento que comparten, por ejemplo, en el siglo XVII Rapin en Réflexions sur la Poétique d'Aristote et sur les ouvrages des poètes anciens et modernes (1674), reeditado en 1675 como Réflexions sur la Poétique de ce temps et sur les ouvrages des poètes anciens et modernes, o Temple en "De la poesía" (1690), quienes, frente a la poesía heroica, manifiestan cierto desdén por canciones, sonetos, odas y elegías, desprecio generalizado que cambió después con la pujanza de los poemas pindáricos y seudopindáricos, que se apartaban ya de las odas menores. Así, en 1704 Dennis agrupaba la poesía lírica mayor, en la que se incluía la oda mayor pindárica junto con la epopeya y la tragedia, frente a la comedia, la sátira y la pequeña oda, entre otras formas. En esta misma línea, el Dr. Johnson distinguía la oda "mayor" de la "menor", por poseer aquélla "sublimidad, arrobamiento y rapidez de transición". 22

Al prestigio de la poesía lírica contribuyó la opinión de que la poesía bíblica era fundamentalmente lírica. Los que después defendían una teoría expresiva de la lírica, y no imitativa, creían que los primeros poemas fueron los líricos, proto-odas o proto-elegías, según que el teorizador "supusiera que la pasión religiosa o la erótica había sido la más potente y compulsiva en expresarse". (ABRAMS 1975: 158) En la línea de Vico, Diderot cree que la espontaneidad apasionada de los pueblos primitivos hace que éstos sean más poéticos y relaciona el ardor poético puro con la oda, situándola en el origen de las manifestaciones poéticas. ${ }^{23} \mathrm{El}$ ardor del que habla Diderot sería, pues, uno de los rasgos estilísticos básicos del género, tal como lo estableció Boileau. Así, la oda llega a ser considerada como la especie de lírica más poética, en opinión de Joseph Trapp, y también como la más antigua, la más embriagadora y la más alejada de la prosa, según Edward Young. Para Jones la poesía se explica por el deseo de expresar la alegría, la pesadumbre, el aborrecimiento por el vicio, etc. Los distintos géneros que se corresponden con tales estados anímicos y sus relativas actitudes vitales y morales serían verdaderamente poéticos. La Allgemeine Theorie der schönen Künste de J.G. Sulzer -cuya primera edición, de 1771-4, fue ampliada en 1792-, obra contemporánea e ideológicamente similar al Ensayo sobre las artes llamadas imitativas, de Sir William Jones, anticipa ya la teoría expresiva romántica. Sulzer sostiene que la lírica fue la forma primordial de la poesía, y declara que el género de la oda constituye la más alta especie poética, en el más intenso grado. Como más tarde Poe, defiende que la intensidad de esta forma poética quintaesenciada pone un limite a su extensión, "pues este estado de alma por su naturaleza misma no puede durar largo tiempo". (ABRAMS 1975: 160-165) Las Naturformen de Goethe contienen ejemplos históricos entre los que se incluye también la oda. Con el sistema de Hegel la oda y el himno aparecen dentro de las formas líricas propiamente dichas, junto con géneros afines, como el ditirambo, el salmo y la canción (lied). (GARCÍA BERRIO-HUERTA CALVO 1992: 47-48, 125) Por su parte, Coleridge, al hablar de lo 'subjetivo' y lo 'objetivo'

\footnotetext{
${ }^{22}$ M.H. Abrams, El espejo y la lámpara. Teoría romántica y tradición crítica (Barcelona, Barral Eds., 1975), pp. 15759.

${ }^{23}$ Vide R. Wellek, Historia de la crítica moderna (1750-1950). I. La segunda mitad del siglo XVIII (Madrid, Gredos, 1969), p. 53
} 
como atributos de las especies poéticas, entiende que la oda lírica más genuina es subjetiva. En este sentido, y como divulgador de las ideas alemanas, siguiendo a Schiller y los Schlegel, junto con Goethe, Henry Crabb Robinson considera la lírica como la literatura en la que se refleja la individualidad del poeta e incluye la oda en este tipo de composición, junto con la elegía, las canciones, etc. (ABRAMS 1975: 428-429) Actualmente, la mayor parte de los teóricos sobre géneros literarios no duda del lirismo puro de la oda y del himno. En esta línea se ha de entender la referencia de Paul de Man a la oda como esencia de la poesía, ligada siempre al canto y la música de los que se acompañaba primitivamente. En efecto, tanto la etimología de oda como la de himno están referidas al canto.

El prestigio de la oda como manifestación pura de lo lírico y género característico de toda la poesía occidental, junto al himno, es evidente por la presencia ininterrumpida de ambos géneros a lo largo de la historia de la literatura. La oda occidental europea se muestra heredera de la oda horaciana, por un lado, con un tono moderado y con homogeneidad estrófica, y, por otro, de la de Píndaro, con forma estrófica triádica y con un tono más elevado y magnífico. Pero, en general, el autor que más influencia ha ejercido es Horacio, introductor en Roma de las variedades métricas de la lírica griega. De hecho, Horacio puede ser considerado "como el realizador estilísticamente puro de la oda". (KAYSER 1958: 449) En algunos de sus poemas más extensos se puede observar la imitación de Píndaro -libro IV de odas-, pero con la métrica eólica, con pasajes más duros y apartándose del tema central. Dado que el tema no determina la oda, se puede decir que el modelo ódico horaciano se caracteriza por la serenidad de su tono y la contemplación tranquila y reflexiva. ${ }^{24}$

Horacio, uno de los autores clásicos más difundidos, es el gran modelo a partir del Renacimiento, desde Petrarca, Tasso, Garcilaso, Fray Luis de León, etc. En la literatura española fray Luis de León es el poeta horaciano por excelencia. La "Oda a la vida retirada", trasunto del Beatus ille horaciano, es uno de sus poemas más característicos. Como en la "Oda de la Magdalena", es clara la morosidad descriptiva horaciana. Otras odas de fray Luis se centran en la naturaleza, el mundo, la ciencia, la historia, el arte, la belleza, la música, la soledad, la mitología, la moralidad, etc. Son composiciones altamente morales, que exaltan la virtud o el contenido patriótico, la pasión amorosa o el carácter religioso. Como Garcilaso, fray Luis también emplea la lira para sus odas, forma métrica que, según Macrí, determina el carácter estructural de la modalidad ódica, en analogía con Horacio y Píndaro. ${ }^{25}$

La oda de métrica homogénea, como la sáfica, la anacreóntica, la asclepiada o la alcaica, es la que normalmente se ha conservado en la tradición de la literatura occidental en cuanto a la métrica, caso de fray Luis, pero también de Lorca, por citar un ejemplo más cercano en el

\footnotetext{
${ }^{24}$ Todo esto ha dado lugar a que se haya criticado, como hizo Byron, la poesía de Horacio por su frialdad. Cfr. E.A. Havelock, The Lyric Genius of Catullus (Oxford, 1939), pp. 182-83; L.P. Wilkinson, Horace and his Lyric Poetry (Cambridge, 1946), pp. 123 y ss.; G. Hinojo Andrés, art. cit., p. 180. Con respecto a las influencias y concomitancias de Horacio y los poetas anteriores, véase L. Bieler, Historia de la literatura romana (Madrid, Gredos, 1982), pp. 218 19. Sobre la originalidad de Horacio en la adaptación de la oda eólica, Vide G. Hinojo Andrés, art. cit., pp. 158-159.

25 Cfr. O. Macrí, "Estudio" a fray Luis de León, Poesías (Barcelona, Crítica, 1982), pp. 45-46; V. Cristóbal, "Morosidad descriptiva en las Odas de Horacio", en J.A. Hernández Guerrero (ed.), Retórica y Poética (Cádiz, Seminario de Teoría de la Literatura, 1991), pp. 123-33.
} 
tiempo. Junto a las formas literarias nacionales propias no han dejado de existir intentos de adaptación de la forma métrica y estrófica latina a la lengua vernácula, como sucede, por ejemplo, en Hölty, Hölderlin o Klopstock. Los españoles adaptaron desde el siglo XVI con éxito la estrofa sáfica al español, que no sólo se utilizó para las odas, aunque aparece en algunas, como la Sáfica a Poncio, de Jovellanos, donde no siempre se respetan los acentos del adónico. (KAYSER 1958: 115-117; PAGE 1975: 318-323; SPANG 1993: 88-89)

Según Kayser, en el siglo XX la oda pierde sus características más propias, especialmente dadas en los siglos XVII y XVIII, porque sus límites son más fluctuantes, ya que los propios poetas no saben, en realidad, qué es una oda y no conocen tampoco autoridades ni modelos. (KAYSER 1958: 218) Es verdad que los inciertos límites entre himno y oda se ven aun más oscurecidos, si cabe, con la revolución formal de toda la poesía del siglo XX y su renuencia a continuar viejos moldes. No obstante, en el siglo $\mathrm{XX}$, en la literatura escrita en lengua española, Rubén Darío escribe poemas que podrían integrarse bien en los esquemas genéricos de la oda y del himno, como muestra, por ejemplo, su "Oda a Mitre". Así ocurre también con F. García Lorca, que escribe varias odas, calificadas explícitamente como tales -"Oda a Walt Whitman", con claro tono moralizante, y la "Oda al rey de Harlem"- en uno de sus libros más rupturistas: Poeta en Nueva York. No hay que olvidar que Lorca se propuso escribir un libro de odas hacia 1928, como consta en la carta dirigida a Melchor Fernández Almagro de septiembre de ese año. ${ }^{26}$ Llegó a escribir la "Oda y Burla de Sesostris y Sardanápalo" y "Oda al toro de Lidia", ambas atípicas. Cabría añadir otros poemas como la "Oda a Salvador Dalî", "Soledad", "Oda al Santísimo Sacramento del Altar" y "Apunte para una oda" o "Apuntes para una oda a Baco y Ciso". También escribieron poemas de tono ódico e hímnico Aleixandre, Dámaso Alonso, Alberti, Jorge Guillén, con Cántico, o Pablo Neruda, con tres volúmenes de odas: Odas elementales, Nuevas odas elementales, y Tercer libro de las odas, en los que se insertan numerosas odas totalmente atípicas, de carácter narrativo y sin apóstrofe. En el siglo XX los géneros de la oda y del himno se mantienen con diferentes características de época y las lógicas variaciones formales y estilísticas, como sucede en algunas odas de Federico García Lorca, por ejemplo. A veces estas modalidades sufren una auténtica transformación en sus estructuras básicas, hasta el punto de que pierden sus rasgos más típicos, se vacian de contenido, a favor de un distanciamiento irónico de la tradición que termina destruyendo sus categorías mínimas, como en algunas odas de Neruda.

Pero la renovación y la transformación de géneros tan asentados en la tradición puede lograrse desde otros presupuestos. La integración de una o varias tradiciones ajenas en la propia escritura es uno de los modos más claros de originalidad. Tomemos, en este sentido, el ejemplo de Luis Cernuda, cuyos estudios sobre literatura, además de su propia poesía, demuestran que conocía bien el género de la oda como manifestación de la poesía más clásica. Así, al referirse a la lírica española del XVIII critica la frialdad de la oda neoclásica tanto en la materia como en la expresión. Ejemplo de esta sequedad a la que llevó la oda neoclásica es Quintana, a quien, junto con Meléndez, alude para mostrar su rechazo hacia este tipo de

${ }^{26}$ Vide F. García Lorca, Obras Completas (Madrid, Aguilar, 1991), vol. III, p. 770. 
poesía. ${ }^{27}$ En sus inicios literarios y como experimento formal clásico, escribe Cernuda "Oda", de Égloga, Elegía, Oda (1927-1928), poema narrativo con pretensiones clasicistas, escrito después de la lectura de Garcilaso de la Vega. En "Oda" se aprecia una exaltación relativa del Dios, aunque apenas existe el apóstrofe propio de la oda clásica; sólo al final, en la última estrofa, se invoca al dios para seguir, desde una moderada exaltación de la hermosura, con la descripción de su marcha y de la naturaleza. Más cerca de fray Luis, aunque sin apóstrofe, está "Homenaje", del mismo libro, poema que, tanto por el tono como por el tema musical, presenta algunos ecos de la "Oda a Salinas", de fray Luis. ${ }^{28}$ Parece que Cernuda quisiera reafirmar a través de Égloga, Elegía, Oda su filiación con la gran tradición clásica. De hecho, en "Historial de un libro" define estos poemas como "ejercicios sobre formas clásicas", (CERNUDA 1994: 631)señalando, asimismo, que suponen una mera continuación respecto a su primer poemario, Perfil del Aire, publicado en 1927. Son conocidas las críticas, en su mayor parte negativas, que recayeron sobre este primer libro cernudiano. Probablemente el deseo de mantener las formas clásicas con poemas estróficos regulares y la referencia a poetas lejanos en el tiempo escondían el deseo de separarse de un modelo más cercano, Jorge Guillén, evitando, así, ser calificado de nuevo como un imitador vacuo y poco original del poeta vallisoletano. Sin embargo, los poemas de Égloga, Elegía, Oda son composiciones que carecen del interés y del valor literarios que poseen otras de La Realidad y el Deseo, y el poeta sevillano era muy consciente de ello cuando las calificó retrospectivamente como simples "ejercicios". Su existencia se justifica por la búsqueda de una tradición prestigiosa que explicara toda la poesía de Cernuda no como el fruto de una copia servil de ciertos poetas contemporáneos -Guillén, Salinas, etc.-, sino como el resultado de la unión de diversas tradiciones, entre ellas la clásica. De hecho, la elección de modalidades genéricas como égloga, elegía, oda y homenaje, y la mención explícita de las mismas en los títulos respectivos -tan poco frecuente en los primeros libros de La Realidad y el Deseo- confirman tal planteamiento.

Cernuda abandona las formas clasicistas de Égloga, Elegía, Oda para pasar a lo que se ha llamado su etapa surrealista, que comprende Un río, un amor y Los placeres prohibidos. Estos libros se explican igualmente por el imperativo de buscar una nueva tradición en la que integrarse. Cernuda no logró nunca olvidar la escasa acogida que tuvo Perfil del Aire. Pruebas de ello son el diálogo "El crítico, el amigo y el poeta" o el último poema de La Realidad y el Deseo, "A sus paisanos". Su poesía y su poética están marcadas, por tanto, por ese angustioso y utópico deseo de encontrar una tradición y unos modelos poco cercanos en el tiempo, ajenos a

27 Vide L. Cernuda, "Observaciones preliminares" a Estudios sobre poesía española contemporánea, en Prosa I (Madrid, Siruela, 1994), p. 77, y “Gustavo Adolfo Bécquer (1836-1871)”, ib., p. 90.

${ }^{28}$ Agustín Delgado señala la coincidencia de figuras mitológicas usadas en el poema de Cernuda y en la "Ode ad florem Gnidi" de Garcilaso, concretamente en el uso del mito de Anaxarete, que aparece transformado en Cernuda. También se alude a la presencia de San Juan de la Cruz. Cfr. A. Delgado, La poética de Luis Cernuda (Madrid, Editora Nacional, 1975), pp. 103-117; M. Ulacia, Luis Cernuda: escritura, cuerpo y deseo (Barcelona, Laia, 1984), pp. 43-48; G. Correa, "Mallarmé y Garcilaso en Cernuda: de Primeras poesías a Égloga, Elegía, Oda", en D. Harris (ed.), Luis Cernuda (Madrid, Taurus, 1977), pp. 238-243; E. Barón Palma, Luis Cernuda: Vida y obra (Sevilla, Editoriales Andaluzas Unidas, 1990), pp. 61-62; J. Talens, El espacio y las máscaras. Introducción a la lectura de Cernuda (Barcelona, Anagrama, 1975), pp. 68-69. 
la literatura propia. ${ }^{29}$ Es precisamente el caso del surrealismo, pero también de la influencia de Hölderlin y de la poesía inglesa, como se verá más adelante. En Los placeres prohibidos (1931), no hay odas propiamente dichas, pero sí mantiene, en cierta manera, la actitud ódica "Diré cómo nacisteis", el primer poema del libro, que se abre con una proclamación y una invocación a los placeres prohibidos, para pasar a la descripción y caracterización de los mismos. Se unen aquí las alusiones personales a ciertas opiniones de tipo moral, que hacen pensar en el estilo sentencioso de la oda, aunque se trate de una moral contraria la sociedad. El poema termina proclamando, a modo de conclusión, la eternidad de los placeres prohibidos y la oposición del poeta frente al mundo, con un tono que se vuelve algo solemne en los momentos finales. Sin embargo, la nueva manera surrealista se agota pronto para el poeta sevillano.

En el libro siguiente, Donde habite el olvido (1932-1933), ya cansado y decepcionado de la "moda" surrealista, hay un poema más acorde con el espíritu y el tono serenos de la oda: "Los fantasmas del deseo", dirigido desde el principio a la tierra madre, que aparece como un ente sobrenatural y eterno a lo largo de toda la composición. Desde el yo personal, Cernuda realiza una primera invocación a la tierra para continuar con la poética narración de un pasado amoroso, en la que se intercalan varios apóstrofes. En la segunda estrofa se habla ya desde el presente, sin alusiones al pasado, con un tono y un ritmo pausados sobre lo terreno y su significado para el poeta y su creación. El tono sentencioso generalizado se mantiene en las reflexiones sobre el amor efímero, en contraste con la eternidad de la tierra. Después de haber elevado a ésta a ser la esencia del amor, de la belleza y de la vida, Cernuda manifiesta su deseo de apresar el mundo divino, representado por lo terreno, para pasar a expresar una visión de la realidad, a través de invocaciones y oraciones resolutivas, sobre la vanidad del mundo y la verdad esencial de la tierra y del deseo.

El último poema de Donde habite el olvido introduce el tono y temas principales de Invocaciones (1934-1935), libro en el que Cernuda inicia una nueva visión y expresión poéticas que se desarrollarán en los posteriores libros. Poemas como "A un muchacho andaluz", "Soliloquio del farero" y "El joven marino" muestran ese cambio, sobre todo por la aparición del poema más largo y discursivo. En los personajes del muchacho andaluz, del farero y del joven marino encarna el poeta un héroe concebido como intermediario entre dioses y hombres, algo que recuerda la poesía de F. Hölderlin, a pesar de que Cernuda la leería en profundidad algo más tarde. El mismo poeta cuenta en "Historial de un libro" que, cuando ya tenía medio escrito Invocaciones, leyó y tradujo a Hölderlin: "Más que mediada ya la colección, antes de componer el "Himno a la tristeza", comencé a leer y a estudiar a Hölderlin, cuyo conocimiento ha sido una de mis mayores experiencias en cuanto poeta (...) Con la colaboración de Gebser, emprendí luego la traducción de algunos poemas (...) Al ir descubriendo, palabra por palabra, el texto de Hölderlin, la hondura y hermosura poética del mismo parecían levantarme hacia lo más alto que pueda ofrecernos la poesía. Así aprendía, no sólo una visión nueva del mundo, sino, consonante con ella, una técnica nueva de la expresión

${ }^{29}$ Cfr. H. Bloom, La angustia de las influencias (Caracas, Monte Avila, 1991). 
poética. Los poemas que entonces traduje aparecieron en Cruz y Raya a comienzos de 1936." ${ }^{30}$ Tal como se desprende de estas palabras, la presencia de Hölderlin es fundamental en esta nueva etapa de la poesía cernudiana.

Los esquemas ódicos griegos se imitaron con frecuencia en la literatura alemana desde el siglo XVIII. A mediados del siglo, F. G. Klopstock compuso varias odas alcaicas, como Hölderlin o Von Platen. Klopstock modificó los modelos clásicos gracias al uso de ritmos libres, la abstracción de las materias y una fuerte influencia de los salmos luteranos. Sin embargo, es Hölderlin el autor más importante en la renovación formal del himno dentro del marco de la modernidad literaria. El estilo sublime y grandioso se deja ver bien sobre todo en sus himnos, por ejemplo en "Hymne an die Menschheit" o "Hymne an die Freiheit", de 1791 y 1792 respectivamente. En Hölderlin el diálogo a través de la Palabra entre dioses y hombres forma parte del himno. Para él, los Dioses hablan por señas, como en el Ión de Platón. ${ }^{31}$ Es lógico pensar que el poeta emplee la modalidad hímnica, por ser la forma lírica más cercana al espíritu exaltado, propio del que habla con un dios. En efecto, como comenta Heidegger, el poeta logra así manifestar su propia esencia permanente. Poniendo al descubierto el Ser, da nombre a los dioses y a todas las cosas, con lo que consigue convertirse en "despertador de las apariencias de irrealidad y de ensueño". (HEIDEGGER 1989: 35) Los himnos de Hölderlin, como los de Goethe, poseen, según Kayser, un tipo de ritmo libre, caudaloso, impetuoso, strömender Rythmus-, de tono elevado, con la plenitud de sonido de un lenguaje solemne, (KAYSER 1958: 342) aspectos que se corresponden con la caracterización que Boileau ofrece para la oda en general.

La confusión terminólogica entre oda e himno se manifiesta claramente en los estudios sobre la poesía de Hölderlin, cuyos poemas, calificados a veces como odas, a veces como himnos, conjugan el estilo apasionado y la presencia continua del yo poético. E. Staiger prefiere la denominación de oda para este tipo de poemas hölderlinianos. Para Staiger la oda es un género que "ofrece una gran tensión entre el estilo lírico y el estilo patético", algo que se podría decir de las odas de Hölderlin, donde "el elemento lírico pertenece a la esfera de la naturaleza íntima, lo patético a la esfera del arte, el cual preserva al poeta de diluirse en una especie de olvido de sí mismo, y de este modo le obliga a una evocación del espíritu vivo en su mundo circundante". Estas características alejarían la oda hölderliniana del modelo horaciano. En Hölderlin la oda está sujeta a un espíritu "que no reconoce presente y cuya mirada se dirige desde el pasado hacia el futuro, para retornar de nuevo al pasado." (STAIGER 1966: 229) Esto es lo que lo diferencia esencialmente de Horacio. Hölderlin, como Coleridge, se presenta en su poesía como un ser divino, como un personaje oracular, por lo que sus odas tienen una mezcla

${ }^{30}$ L. Cernuda, "Historial de un libro", pp. 640-41. En 1935 Cernuda publicó una mala traducción de una selección de poemas de Hölderlin con una nota introductoria. Sobre las traducciones. más cernudianas que hölderlinianas, vide J. Talens, op. cit., pp. 383-87. En una carta a Nieves Mathews del 15 de diciembre de 1942 desde Glasgow, Cernuda reconoce la importancia del poeta alemán: "Para mí la lectura de Hölderlin fue una intuición nueva de la poesía y una visión distinta de la realidad." Vide R. Martínez Nadal, Españoles en la Gran Bretaña. Luis Cernuda. El hombre y sus temas (Madrid, Hiperión, 1983), p. 118.

${ }^{31}$ Vide M. Heidegger, Hölderlin y la esencia de la poesía (ed. de J.D. García Bacca, Barcelona, Anthropos, 1989), pp. $25-26$ y 74. 
de lo clásico y de la imaginería bíblica religiosa con personificaciones grandiosas propias del estilo sublime del XVIII, ${ }^{32}$ de ahí que sus odas -si se prefiere esta denominación- sean hímnicas, complejas, místicas y sublimes.

El modelo hölderliniano supuso en la poesía de Luis Cernuda un cambio considerable. El poema largo va a ser, así, consolidado, para el resto de su producción. Dentro de Invocaciones, encontramos un tono diferente, ya advertido por Cernuda en sus apreciaciones sobre Hölderlin, especialmente cuando señala el modo en que la lectura del poeta alemán provoca una elevación espiritual que, sin duda, remite al concepto de lo sublime, típico de los poemas hímnicos. Este nuevo tono que Cernuda persigue para su obra se puede apreciar en los poemas largos, de tono ódico e hímnico, como "A un muchacho andaluz", "Soliloquio del farero", "Por unos tulipanes amarillos", "La gloria del poeta", "Dans ma péniche", "El joven marino", "Himno a la tristeza" y "A las estatuas de los dioses", por ejemplo. No resulta extraño que Cernuda en su "Historial de un libro" se refiera con desagrado, pasados ya algunos años, a la ampulosidad de algunos poemas de Invocaciones.

En "A un muchacho andaluz" se canta desde el yo al joven al que se invoca desde el principio y al que se identifica con el amor misterioso. La descripción se une a la narración poética de la muerte del muchacho ahogado en el mar, tras la que, como tercer momento, se concluye con la exaltación de dioses terrenos y la negación del cristianismo. El contenido de protesta se ha amortiguado con respecto a Los placeres prohibidos, pero la intención crítica, de un moralismo sui generis, es similar. "El joven marino", más cercano a la elegía, al igual que "Por unos tulipanes amarillos", está escrito con verbos en pasado y dirigido al joven cuya muerte se narra, quien queda elevado a la categoría de dios.

"Soliloquio del farero" es un canto a la soledad que se inicia también con una invocación, a la que sigue la narración del poeta-niño, con referencias personales que ocupan la parte central y la casi totalidad del poema, para volver a invocar al final a la soledad como verdad última y concluir con la necesidad de la misma para el poeta. Más cerca del himno está "La gloria del poeta", por su invocación al demonio, con claros ecos baudelairianos. Pero la narración y descripción del demonio junto a la identificación con el poeta, con abundantes referencias personales, la exposición de los deseos, la superioridad del poeta frente a los hombres, las continuas referencias y exhortaciones al demonio y la conclusión sentenciosa de que sólo la muerte puede reconfortar al poeta amortiguan el tono hímnico y exaltado en favor de la actitud ódica, más personal. Algo similar sucede en "Dans ma péniche", con una primera invocación al amor, a la que siguen la descripción de los amantes y nuevas invocaciones a éstos, con referencias personales del poeta, que se sitúa junto con el deseo y frente al dios cristiano, en un plano superior. La conclusión final está centrada en la superioridad sobre el amor del deseo y de la libertad, ligados a la verdadera vida.

32 Cfr. M.H. Abrams, Natural Supernaturalism. Tradition and Revolution in Romantic Literature (Nueva YorkLondres, W.W. Norton and Company, 1973), p. 344. 
Cernuda encontró en el poeta alemán, además, la importancia de los mitos antiguos como expresión de las emociones primarias del hombre, el amor, el poder, la experiencia de la belleza y de la poesía. Hölderlin le brindó la posibilidad de recuperar los dioses paganos y su poder frente al triste dios cristiano, de ahí poemas como "A las estatuas de los dioses" y, más tarde, "Resaca en Sansueña" de Las nubes (1937-1940), entre otros. La naturaleza, como en Hölderlin, se torna en Cernuda algo esencial, encarnación de la verdad y del deseo, idea que ya había aparecido en el último poema de Donde habite el olvido.

A partir de "Himno a la tristeza", poema que, en opinión de Coleman, inicia el camino de su poesía posterior, puede apreciarse la impronta de Hölderlin, tras la lectura detenida de su obra. El poema supone la entrada a la poesía meditativa. Desde el mismo título recuerda los himnos de Hölderlin, además de otros poemas de Keats, Shelley y Coleridge sobre el mismo tópico de la tristeza. Cernuda entra de lleno, así, en la tradición romántica europea. Pero Coleman al referirse a este poema no habla de himno, sino de oda. Como indica, "Himno a la tristeza" comienza in medias res, bruscamente, con una manera dramática que es muestra del nuevo estilo cernudiano, con fuerte presencia de la melancolía, encabalgamientos que refrenan el tono para retardar el ritmo de lectura y dar mayor pesadez a los versos. ${ }^{33}$ En realidad, lo que hace Cernuda es dar solemnidad serena a lo que debió llamarse oda y no himno. El nuevo estilo es más ampuloso y grandilocuente, pero el yo personal nunca se diluye en la exaltación hímnica. Incluso en la invocación a la tristeza como "madre inmortal" Cernuda no hace uso de las admiraciones. La designación de himno, en realidad, se debe al deseo cernudiano de elevar la tristeza a una categoría divina, de ahí el título, pero el desarrollo del poema se acerca mucho más al tono ódico. Después de la invocación el poeta vuelve a las referencias personales, identificándose a veces con un dios, pero con un sentido estoico de su soledad. El dolor va unido siempre a la tarea del poeta y el desarrollo poemático conduce finalmente a la afirmación final de su soledad, que sólo encuentra consuelo en la tristeza.

"A las estatuas de los dioses" es otra de las composiciones de Invocaciones de influencia claramente hölderliniana, apreciable tanto en la sintaxis como en el vocabulario. (ULACIA 1984: 111; COLEMAN 1969: 38-41) Como "Himno a la tristeza", se abre con una apelación directa a los dioses, a la que sigue una narración en la que se recuerdan los gloriosos tiempos pasados, narración que va acompañada del deseo por devolver a los dioses la dignidad perdida, y de las alusiones al propio poeta como único ser que sueña con ellos, convertido casi en parte esencial de lo divino. El acento que prevalece, sin embargo, es el íntimo y personal, por lo que también predomina aquí el tono ódico. Cernuda tomará, pues, de Hölderlin no el sentido profético, más exaltado, sino el moralista y personalizado, más cercano a su temperamento, por lo que su tono resulta más ódico que hímnico. En

${ }^{33}$ Cfr. A. Coleman, Other Voices: A Study of the Late Poetry of Luis Cernuda (Chapel Hill, The University of North Carolina Press, 1969), pp. 32-35; M. Ulacia, op. cit., p. 112. 
realidad, este nuevo tipo de poema abre el desarrollo lírico posterior de La Realidad y el Deseo: poemas narrativos, largos, meditativos, con preocupaciones metafísicas. ${ }^{34}$

En la etapa del exilio en Inglaterra, Cernuda tendría oportunidad de leer en su lengua original a los poetas ingleses, especialmente los metafísicos y los románticos, que, sin duda contribuyeron a afianzar y acrisolar el nuevo camino discursivo y metafísico emprendido en Invocaciones. En una carta a E.M. Wilson del 17 de marzo de 1948 desde Mount Holyoke College, señala la importancia que para él tuvo la poesía inglesa: "No piense que me olvido de Inglaterra, porque como es natural la recuerdo mucho ahora, y comprendo cuánto la debo espiritualmente. Quizás mi estancia allí, de cerca de diez años, ha sido la fase más rica de mi vida hasta ahora, si no como molde primero, como refinación de lo que a ella llevé conmigo." Y en "Historial de un libro" reconoce también su deuda con la literatura anglosajona: "Si no hubiese regresado, aprendiendo la lengua inglesa y, en lo posible, a conocer el país, me faltaría la experiencia más considerable de mis años maduros (...) Aprendí mucho de la poesía inglesa, sin cuya lectura y estudio mis versos serían hoy otra cosa, no sé si mejor o peor, pero sin duda otra cosa. Creo que fue Pascal quien escribió: "no me buscarías si no me hubieras encontrado" y si yo busqué aquella enseñanza y experiencia de la poesía inglesa fue porque ya la había encontrado, porque para ella estaba predispuesto." ${ }^{, 35}$

Desea Cernuda escribir de una manera más objetiva, más seria y grave, cercana al espíritu meditativo y moralista de algunos poetas ingleses. No hay que olvidar tampoco que, aparte de las traducciones que hizo, dedicó un libro a algunos de estos poetas: Pensamiento poético en la lírica inglesa, en el que destacaba los rasgos que más le interesaron y que están presentes en su propia actividad poética. Así, sobre Wordsworth, Coleridge, Keats, Shelley, Byron y Blake, por ejemplo, dice Cernuda que la mayoría "son moralistas y no ocultan su propósito de mejorar, corregir y reformar, tratando de hallar en la naturaleza humana, y sobre todo en la vida imaginativa, nuevas creencias sustentadoras. El poeta no es sólo un poeta, sino el intérprete de la creación; de ahí que la mayoría de ellos adopten una posición metafísica y una posición política." ${ }^{36}$ Insiste en varias ocasiones en el tono meditativo y filosófico de estos escritores, a los que, no por ello, es ajena la noción de la poesía como visión e imaginación. Hay que tener en cuenta, además, que en Poesía y Literatura (1960) dedica un estudio a los poetas clásicos, con referencias a Garcilaso, fray Luis y San Juan, y otro a los poetas metafísicos españoles, entre los que incluye a Jorge Manrique, Aldana y el autor de la "Epístola Moral a Fabio", en lo que se aprecia de nuevo

\footnotetext{
${ }^{34}$ También Talens ha señalado la importancia de Invocaciones como el libro en el que hace su aparición en poema lírico-narrativo en la obra de Cernuda. Cfr. J. Talens, op. cit., p. 96.

${ }^{35}$ L. Cernuda, "Historial de un libro", p. 645. Vide R. Martínez Nadal, op. cit., p. 184.

${ }^{36}$ L. Cernuda, Pensamiento poético en la lírica inglesa, en Prosa I, p. 262. B. Hughes señala influencias posibles de Donne, Herbert, Marvell, los metafísicos en general, Shakespeare, Blake, Keats, Browning, Wordsworth, Shelley, entre otros, en la poesía de Cernuda a partir de Las Nubes. Cfr. B. Hughes, Luis Cernuda and the Modern English Poets (Alicante, Universidad, 1987).
} 
el interés del poeta de La Realidad y el Deseo por los aspectos morales y reflexivos de la literatura.

En la poesía inglesa del XVII pocos escritores escriben odas en la línea horaciana. Sin embargo, la oda pindárica se impone como modalidad prestigiosa a partir de 1629, fecha en que apareció la primera gran imitación de Píndaro en inglés: la "Ode on the Death of Sir $\mathrm{H}$. Morison" de Ben Jonson, con la estructura clásica de estrofa, antistrofa y epodo, indicada con los términos de turn, compter-turn y stand. En el mismo año Milton comienza su gran oda "On the Morning of Christ's Nativity", en una forma estrófica ya regular. El género alcanzaría gran popularidad con las Pindarique Odes de Abraham Cowley. La fortuna de la poesía lírica como género serio aparece en 1651 en Inglaterra con las imitaciones pindáricas de Cowley, que inauguran, en opinión de Abrams, la boga de la "oda mayor". Pero la oda pindárica inglesa, introducida por Cowley y usada posteriormente en el neoclasicismo no suele mantener la estructura antigua triádica, sino que es libre en la construcción estrófica y en la rima. Son odas con un tono elevado y un lenguaje solemne, que se corresponden con lo que Kayser llama "ritmo caudaloso" o impetuoso -strömender Rythmus-, caracterización no lejana de la que ofrece Boileau en su Art Poétique. Se trata, pues, de poemas fogosos, impetuosos e irregulares, a los que los críticos han aplicado el concepto de Longino sobre lo sublime, frente a la más denostada oda menor. Estas odas mayores fueron luego cultivadas, además, por Warton, Gray y Collins, entre otros. En el siglo XVIII, hay que destacar a Williams Collins, poeta británico, cuya obra principal es una colección de Odes on several descriptive and allegorical subjects (1747), de escasa acogida en su época. Collins está unido por el tono profético y protestante, que sigue a Spenser y a Milton, a los poetas románticos ingleses, como Keats, Blake y Wordsworth. ${ }^{37}$ En esta línea de la oda mayor pindárica se encuentran también Dryden y Thomas Gray.

La oda romántica inglesa comienza con la composición de Coleridge "Dejection: An Ode", de 1802, y con la oda seudopindárica de Wordsworth "Ode: Intimations of Immortality", escrita entre 1802-4 y publicada en 1815. Ésta, con versos variados, ritmo complejo y estrofas diversas, ha sido considerada la mejor oda pindárica de la literatura inglesa. Otras odas, no pindáricas, de William Wordsworth son "To the Cuckoo", "A Farewell", "To a Highland Girl", "To a Skylark". También escriben odas en esta etapa Shelley, Keats, Blake y, ocasionalmente, Byron. La oda tiene, pues, en este periodo, un resurgimiento paralelo al de la poesía lírica, antes despreciada. La "Ode to the West Wind" (1819), de Shelley, es un poema religioso, casi como la oda dedicada a la alondra, compuesta un año más tarde. Keats escribe textos como "Ode on a Grecian Urn", "To a Nightingale", "Ode to Psique" o "To Autumn". Éste último, traducido por Cernuda, es para H. Bloom, el más sutil y hermoso del autor. ${ }^{38}$ Todos estos poemas están escritos en estrofas regulares, derivadas no de Horacio, sino de los experimentos de Keats sobre el soneto.

\footnotetext{
${ }^{37}$ H. Bloom, Los poetas visionarios del Romanticismo inglés (Barcelona, Barral Eds., 1974), p.15.

${ }^{38}$ Cfr. ib., pp. 135, 210-213 y 292-299. Con respecto a los himnos, desde la doble tradición, litúrgica y literaria, inaugurada por Prudencio y continuada después, escribe Keats su "Hymn to Apollo" y también Shelley los himnos "To Intellectual Beauty", "Of Apollo" y "Of Pan". Para H. Bloom, la influencia de La Nueva Eloísa de Rousseau se une a
} 
Pero lo más interesante de la tradición poética inglesa es que las odas de algunos de estos autores pertenecen a un tipo de composición característica del romanticismo. Entre tales poemas, algunos de los cuales son odas, se incluyen los siguientes: de Coleridge, "Eolian Harp", "Frost at Midnight", "Fears in Solitude" y "Dejection: An Ode"; de Wordsworth, "Titern Abbey", "Ode: Intimations of Immortality" y "Elegiac Stanzas Suggested by a Picture of Peele Castle in a Storm"; de Shelley, "Stanzas Written in Dejection" y "Ode to the West Wind"; de Keats, la "Ode to a Nightingale". De los románticos, sólo se excluye a Byron en esta clase de poemas. Todos ellos presentan un hablante que comienza describiendo el paisaje, para evocar alguna vivencia, iniciando, así, un proceso en el que el recuerdo, los pensamientos, los sentimientos, etc., están relacionados con dicho paisaje. Se pasa, pues, de la descripción a la meditación, en la que el personaje, tras una serie de comentarios, se enfrenta a un momento trágico o llega a una decisión moral o resuelve un problema de tipo emocional. A menudo el poema vuelve al principio, al paisaje, pero ya con un estado de ánimo diferente, tras la meditación. Este género romántico, a veces llamado the descriptive-meditative poem, ha sido calificado por Abrams como the greater Romantic lyric, sugiriendo no el hecho de que estos poemas sean lo mejores de la época, sino que desplazan lo que los críticos neoclásicos han llamado the greater ode, la oda pindárica elevada frente a la llamada menor, más cerca de la pauta horaciana. Esta modalidad ha encontrado eco en autores posteriores como Matthew Arnold, Walt Whitman, Wallace Stevens, W.H. Auden y, en la literatura española, Luis Cernuda.

Evidentemente, el hecho de partir de la naturaleza para la reflexión no era algo totalmente novedoso, pero con el romanticismo se impuso la moda de hablar de temas serios -vida, muerte, amor, gozo, Dios- junto con la referencia al paisaje. Tiene especial interés por ser la más temprana invención romántica, especialmente practicada por Coleridge -también, aunque menos, por Wordsworth-, que fue quien inauguró the greater Romantic lyric, establecido ya este esquema. Claro está que hay antecedentes, aunque no en las fórmulas clásicas inglesas, como podría pensarse a partir de las odas Collins. Para descubrir los verdaderos precursores, Abrams se centra en la precisión con la que se describe el paisaje, dando el lugar e incluso el momento exacto, con un escrúpulo total, como en Wordsworth, que especificaba al principio la circunstancias personales de sus poemas. En el siglo XVIII existían composiciones muy populares que detallaban también en el título la localización y describían una escena que sugería unos pensamientos; eran los llamados poemas local por loco-descriptive, de donde se desarrollaría este tipo de textos románticos. En general, como apunta Abrams, se dice que Sir John Denham fue el autor del género con su "Cooper's Hill", cuya primera versión es de 1642. Thomas Gray, con su "Ode on a Distant Prospect of Eton College", de 1747, también proporciona evidencia de que el poema local evolucionó hacia el tipo romántico. Pero, yendo más lejos en la tradición literaria inglesa, hay que mencionar los poemas devotos del XVII que incluían la meditación como elemento básico, al igual que sucede en algunas de las composiciones

la de Wordsworth en el "Himno a la belleza intelectual" de Shelley, donde intelectual hace referencia a espiritual o más allá de los sentidos. El tema del himno es similar al de la oda "Sugerencias" de Wordsworth. Cfr. H. Bloom, ib., p. 284 . 
románticas citadas. En The Poetry of Meditation, Martz ha hablado de la importancia que para los poetas religiosos metafísicos tuvieron los devocionarios, en los que el procedimiento recomendado para la reflexión se dividía en tres partes, siguiendo las directrices de San Ignacio de Loyola. El primer momento correspondía a la composición de lugar, en que se contemplaba detenidamente el entorno; el segundo, a la meditación propiamente dicha, y el último, a los resultados de esa meditación y a la voluntad, es decir, a la conclusión, que podía tener forma de coloquio, o de plegaria o concretarse en unas palabras dirigidas a Dios. Los escasos poemas meditativos del siglo XVII mantienen estas fórmulas de los devocionarios católicos y anglicanos. Poetas metafísicos en los que encontramos estas estructuras son Vaughan y George Herbert. De aquí provendría la modalidad romántica de the greater Romantic lyric. Las meditaciones románticas, por otro lado, a veces provocan momentos críticos, cercanos a las crisis espirituales de los poetas religiosos. La influencia de los metafísicos se extiende hasta el punto de que los románticos dan a su expresión algunos tintes teológicos, e incluso llegan a apostrofar no a un ser humano, real o imaginado, sino a Dios o algún espíritu de la naturaleza de carácter superior, como si fuese una plegaria formal, caso de la "Ode to the West Wind", o incluso llegan a la fórmula de la bendición formal, como en "Frost at Midnight" y "Dejection", de Coleridge, y en "Tintern Abbey", de Wordsworth. Evidentemente, hay diferencias que afectan especialmente a la composición de lugar, más concreta en los románticos y más general en los metafísicos. ${ }^{39}$

En La Nubes, un libro crucial en el momento de transición hacia la poesía meditativa, el tono ódico de Cernuda se extiende a muchos poemas, aunque no siempre aparece el apóstrofe. Un poema de tono ódico es "La visita de Dios", en el que el poeta, desde sus circunstancias personales, inicia un recorrido por sus recuerdos, que le llevan a reflexionar sobre la existencia humana, el amor, el tiempo, y a criticar la sociedad, aunque de modo moderado. Es un poema jalonado de preguntas y sólo muy al final encontramos el tardío apóstrofe a Dios, como si no bubiera acudido antes al dolor del hombre, como si no existiera y por ello se hubiera tardado tanto en mencionar. Tras ello vienen la plegaria y la petición.

Mucho más cercano a la oda es el poema final de Las Nubes: "El ruiseñor sobre la piedra", con estructura tripartita. Es éste el primer poema del exilio en el que se aprecia claramente el influjo del poema meditativo romántico. Comienza con una invocación al Escorial bajo las metáforas del lirio y del ruiseñor. La descripción idealizada, desde el recuerdo del poeta, llega hasta el verso 15 y da lugar a una larga reflexión sobre la vida con referencias personales al destierro-, sobre el amor, sobre el trágico ocio del poeta. La lírica meditación, serena y, en ocasiones, algo sentenciosa, conduce a la proclamación final, de carácter conclusivo, de la eternidad del Escorial como símbolo de España y de su raza. Se trata de una composición en la que es patente el influjo de la poesía meditativa de

39 Vide M.H. Abrams, "Structure and Style in the Greater Romantic Lyric", en H. Bloom (ed.), Romanticism and Consciousness. Essays in Criticism (Nueva York-Londres, W.W. Norton and Company, 1970), pp. 201-228; L.L. Martz, The Poetry of Meditation (New Haven-Londres, Yale University Press, 1962). 
práctica religiosa. En ella es la mirada interior, que recrea plásticamente los recuerdos ligados a un lugar emblemático del pasado, la que provoca el desarrollo meditativo.

Otros poemas ajustados claramente a un esquema similar son "Elegía anticipada", "Río vespertino", 40 "Las ruinas", "Otros tulipanes amarillos", "Vereda del cuco", de Como quien espera el alba (1941-1944), "La ventana", "La escarcha", "El árbol", "Otras ruinas", "El César", de Vivir sin estar viviendo (1944-1949), "Desolación de la Quimera" y "Epílogo", de Desolación de la Quimera (1956-1962), entre otros. En ellos, el punto de partida para la reflexión sigue siendo un paisaje que, o bien se finge como presente en el momento del discurso, o bien se evoca desde el recuerdo, gracias a la memoria y a la mirada interior que lo actualiza y recupera. En el caso de "El César" la estructura meditativa se combina con la técnica del monólogo dramático, como también sucede en "Desolación de la Quimera", aunque este último combina la voz poético-narrativa para la descripción inicial del lugar y las conclusiones finales con el monólogo dramático de la Quimera, que ocupa el centro de la composición y se corresponde con el desarrollo meditativo.

Uno de los poemas más característicos de Cernuda en la adaptación del poema meditativo es "Las ruinas". En efecto, se inicia con la larga descripción de unas ruinas, marmóreas, solitarias y bellas en su decadencia. Las tumbas y los cipreses contrastan con la hermosura del mirto, de las aguas libres, de las hojas que tiemblan en las ramas, de la luz incierta de la luna. La contraposición continua entre muerte y vida, ausencia y presencia, conduce a la reflexión sobre el tiempo y la vida breve del hombre, quien se rebela contra su condición mortal en su tenaz búsqueda de la belleza y la eternidad. La invocación desesperada a Dios y las preguntas que el poeta le dirige para, a continuación, negar su existencia como modo de rebeldía más radical se corresponden con el característico momento de crisis de este tipo de composiciones:

"Oh Dios. Tú que nos has hecho

Para morir, ¿por qué nos infundiste

La sed de eternidad, que hace al poeta?

¿Puedes dejar así, siglo tras siglo,

Caer como vilanos que deshace un soplo

Los hijos de la luz en la tinieblas avara?

Mas tú no existes. Eres tan sólo el nombre

Que da el hombre a su miedo y su impotencia".

Tras este momento crítico, breve y angustiado, pero decisivo, en el que ha derivado la reflexión, el poeta proclama la hermosura del instante y la necesidad de buscar la eternidad

\footnotetext{
40 Sobre "El ruiseñor sobre la piedra", "Elegía anticipada" y "Río vespertino", Vide J.A. Valente, "Luis Cernuda y la poesía de la meditación”, La caña gris, núms. 6-8 (1962), pp. 33 y ss.
} 
en la belleza efímera, aceptando finalmente su condición mortal. El poema, de estructura circular, termina con la vuelta al paisaje nocturno de las ruinas, aunque ya con la serenidad y la conformidad espirituales dadas por la voluntad de vivir de acuerdo con la naturaleza propia del ser humano. ${ }^{41}$

La influencia literaria inglesa se une en este y otros textos a la tendencia propia hacia el tono sentencioso, sereno y discursivo de la oda, tono al que habría que añadir, como rasgos básicos del género, la estructura tripartita y la presencia de los apóstrofes. Existen en la poesía del exilio otros poemas que pueden calificarse como odas, por su tono y su estructura, pero el logro mayor de Luis Cernuda fue precisamente la adaptación del poema meditativo anglosajón, de claro acento ódico, a la literatura española, hecho que ha emparentado definitivamente al poeta sevillano con la gran tradición moral y metafísica europea, ligada, como se ha comprobado ya, a la actitud y el espíritu de la oda. ${ }^{42}$

41 Para H. Pato, el poema se puede dividir en cinco partes que corresponden a diferentes niveles de pensamiento: observación, evocación meditativa, invocación, meditación, contemplación. Por otra parte, señala Pato que su final es representativo por su resolución filosófica. Cfr. H. Pato, Los finales poemáticos en la obra de Luis Cernuda (Boulder, Society of Spanish and Spanish-American Studies, 1988), pp. 69 y ss.

${ }^{42}$ Sobre la influencia de la tradición meditativa en la prosa de Cernuda, véase J. Valender, Cernuda y el poema en prosa (Londres, Tamesis Books, 1984), pp. 48-49. Para C.P. Otero Luis Cernuda "es el gran poeta metafísico de su generación". Cfr. C.P. Otero, "La tercera salida de La realidad y el deseo", en Letras I (Londres, Tamesis Books, 1966), p. 174. 
. 


\section{NORMAS DE PUBLICACIÓN}

1. Los originales deberán ser inéditos y no estar aprobados para su publicación por ninguna otra entidad.

2. Los originales recibidos serán examinados por miembros del Consejo de Redacción y/o del Consejo Asesor de la Revista.

3. La publicación de artículos en las revistas de la Universidad de Sevilla no da derecho a remuneración alguna. Los derechos de edición son de la Facultad de Filología de la Universidad de Sevilla y es necesario su permiso para cualquier reproducción. En todo caso, será preciso citar la procedencia en cualquier reproducción parcial o total.

5. Los autores tendrán derecho a veinte separatas de los artículos y tres de las reseñas.

\section{NORMAS DE PRESENTACIÓN}

1. Los originales definitivos se enviarán al Secretario de la revista (Facultad de Filología, Departamento de Lengua Española, Lingüística y Teoría de la Literatura, C/ Palos de la Frontera, s/n, 41004 Sevilla). Irán precedidos de una hoja en la que figure el título del trabajo, el nombre del autor (o autores), su dirección y el teléfono y el nombre de la institución a la que pertenece. Asimismo, se hará constar la fecha de envío del trabajo.

2. Los artículos y notas tendrán una extensión máxima de veinticinco y ocho páginas respectivamente, a razón de treinta líneas por página y setenta caracteres por línea como máximo. Las reseñas tendrán una extensión máxima de tres páginas. El autor especificará si presenta el trabajo en calidad de artículo o de nota. En todo caso, el Consejo de Redacción se reserva el derecho de proponer al autor la inclusión de su trabajo en una sección distinta de la indicada.

3. Se ha de enviar dos copias impresas de cada manuscrito. Debe adjuntarse una copia del documento original definitivo en soporte informático. Sólo se aceptarán disquettes de 3'5 pulgadas formateados en sistema MS-DOS. Pueden enviarse ficheros creados con las aplicaciones siguientes: WORDPERFECT, MS WORD, LOTUS AMIPRO O WORDPRO'97, todas ellas en versión Windows. Los ficheros de texto ASCII también son aceptados, debiendo llevar las notas a pie de página enumeradas consecutivamente al final del trabajo.

4. Cada artículo irá acompañado de un resumen de no más de quince líneas (aprox. 250 palabras) redactado en inglés, sin la palabra "Abstract".

5. Los cuadros, mapas, gráficos, tablas, figuras, etc., que se entreguen con los trabajos deberán ser originales y se presentarán preferentemente en papel vegetal y perfectamente rotulados. Todos irán numerados y llevarán un breve pie o leyenda para su identificación. También se indicará el lugar aproximado de su colocación.

\section{NORMALIZACIÓN DE CITAS Y NOTAS}

1. Los números indicativos de nota serán numerales arábigos, escritos ligeramente por encima de la línea de escritura, e inmediatamente después del material al que se refiere. No irán entre paréntesis.

2. Si la referencia es breve, puede insertarse entre paréntesis en el texto (Ej. Eliot 1920:37), pero la primera referencia completa de un trabajo debe aparecer en una nota o al final del trabajo.

3. Las citas bibliográficas atenderán a las normas siguientes:

LIBROS: INICIAL. APELLIDO DEL AUTOR, TíTULO (CIUDAD AÑO) PÁGINAS

Ejemplo: T. S. Eliot, The Sacred Wood (London 1920) 36-38.

REVISTAS: INICIAL. APELLIDO DEL AUTOR, "TÍTULO DEL ARTÍCULO", REVISTA No (AÑO) PÁGINAS

Ejemplo: A. Díaz Tejera, "El género en griego clásico: descripción sincrónica y explicación diacrónica", Revista Española de Lingüística 11 (1981) 13-31. 
